\title{
Emotion and Cognition: The Case of Military Personals
}

\author{
Abdelmajid Naceur ${ }^{1}$, Wafa Ferchichi' ${ }^{2}$, Rahme Boualleg2 \\ ${ }^{1}$ Education, Cognition, Tice and Didactic (ECOTIDI), Higher Institute of Education (ISEFC), Tunis, Tunisia \\ ${ }^{2}$ Education, Cognition, Tice and Didactic (ECOTIDI), Tunis, Tunisia \\ Email: psynaceur@yahoo.fr
}

How to cite this paper: Naceur, A., Ferchichi, W. and Boualleg, R. (2017) Emotion and Cognition: The Case of Military Personals. World Journal of Neuroscience, 7 , 1-18.

https://doi.org/10.4236/wjns.2017.71001

Received: August 16, 2016

Accepted: December 13, 2016

Published: December 16, 2016

Copyright $\odot 2017$ by authors and Scientific Research Publishing Inc. This work is licensed under the Creative Commons Attribution International License (CC BY 4.0).

http://creativecommons.org/licenses/by/4.0/

(c) $\underset{\mathrm{EY}}{ }$ Open Access

\begin{abstract}
Tunisian veterans experienced uncommon circumstances that put their lives in permanent threat. In this context, it is crucial to understand the adaptive strategy they tend to use. Distress takes place when military veterans use ineffective coping styles within a taxing and high demanding context. The aim of the current study was to estimate the link between coping styles, the psychological well-being and work related stress. A second goal is to extend the analyses for clinical diagnosis and providing a specific interpretation of the military's behavior. We investigated these issues in a qualitative study. Findings are discussed in the context of a theoretical framework of transactional approach. This was a survey with a random sample of military officers stratified by rank $(n=26)$. Coping strategy scale (CSS), perceived stress (PSS) and psychological well-being (PWBM) were administrated to veterans from different ranks (high ranks and low ranks). Additionally, Chi square frequencies were constructed between the perceived stress scales, coping strategies and psychological well-being. Results were consistent and showed a best fit between perceived stress and ranks of officers $(\mathrm{X} 2=0.026, p<0.05)$. Problem focused coping is known to be more effective than other coping strategies, but our findings add the fact that veterans using this style are completely deprived from happiness. The data emphasized specifically the absence of difference between men and women, or between the various ranks regarding coping styles; otherwise seniority plays a role in modulating this relationship. Comparison tests showed a significant difference across years of employment in terms of well-being: more senior participants had more self-esteem than new ones $(\mathrm{X} 2=0.010, p<0.05)$. Our results reveal that only two major coping strategies are predominantly used: problem resolution and avoidance. This further clarifies that military personals are incapable to maintain emotional balance and a satisfied image of themselves, complete absence of happiness and balance.
\end{abstract}




\section{Keywords}

Emotion, Stress, Well-Being, Cognition, Coping-Military Personals

\section{Introduction}

Historically, the Tunisian army was merely absent while speaking about its role in shaping the social and political landscape of the country. Even though, during the protectorate era, that is to say under the French rule, the Tunisian army served as an important source of manpower. Furthermore, the Tunis's military has been kept marginalized, removed from the political and economic power; it was underfunded as well as under-equipped. The Tunisian National Army has only recently come to center stage in the 2011's after the crackdown of the Ben Ali's iron-clad rule. Therefore, the military is compelled to answer several exigencies such as long and unpredictable duty hours, periodic separation from family, geographic mobility, pressure to conform to standard behavior, risk of service member injury or death and disciplinary code.

Since the set-up of the national army in 1965, few researches have targeted the military field. However, with the emergence of unexpected events that necessitated its urgent interference whether within the territory or on the borders, it has come an interesting sphere of multiple studies that triggered sociology as well as psychology, because of the acute stress, and the intense exposure on the battlefield which put the soldiers' life under threat as well as working in a high-risk environment. What's more, the "Terrorism" which itself is considered as a psychological weapon, since a terrorist act tends to be methodical and planned. It aims to obtain a behavior change of a target group. Thus, such act has a purpose that goes beyond the simple completion of the act.

The ongoing pressure over military officers and soldiers within a destabilized context has ignited the interest to wonder about the process in which they tend to cope with psychological stress. Can coping styles be a predictor of well-being within a stressful situations? Does seniority play a role in coping with stressfulness? Do high-rank officers bear more pressure than low-rank officers? Can the length of work service within military modulate the response to the demanding work situations? Which coping strategy (problem-focused coping or emotion-focused coping) is more effective to overcome distress? Do women response differently to perceived stress?

Basically, it is assumed that the modification of the appraisal may contribute to the improvement of coping strategies, and therefore enhancing well-being.

A lot of researchers were interested in the effectiveness of the usage of coping strategies in the stress management. As a matter of fact, it has been examined that some coping strategies have beneficial effects that allow a good endurance of pressure in a precise situation, while other coping styles may affect negatively an individual's mental health [1]. The aim of this study is to determine which cop- 
ing style is frequently used by military veterans, and to figure out its effect on the psychological well-being.

\section{The Transactional Model of Stress}

It was not until the late eighteenth and nineteenth century that the meaning of stress has altered to refer to a period of intense industrial and scientific progress. The usage of language has shifted to accommodate with the spirit of the age. People started to use terms such stress, strain, resilience, pressure, elasticity to express the effect of materials. It is commonly refer the psychological use of stress to Hans Selye in 1956 [2], but this wrongly assumed because this psychological concept has occurred before. Seyle defines stress as "the nonspecific response of the body to any demand, whether it is caused by, or results in, pleasant or unpleasant conditions".

Truth to tell, Selye has developed this concept forward to introduce a three phase process, referred as the General Adaption Syndrome (GAS). He thought that a person reacts to external stressors by mobilizing his or her physical resources to handle his situation whether by escape or by confrontation. This phase is called alarm stage. Then, it comes the resistance phase which refers to the way a person cope with the situation. The third phase is related to the exhaustion, and this occurs in case an individual is excessively exposed to a stressor that cannot escape. Over time, with Walter Cannon in 1994 [3] the term stress has been developed, and was related to the fight or flight response.

Griffin and Moorhead (2009) [4] within a similar context stated that "stress is a person's adaptive response to stimulus that places excessive psychological or physical demands on that person". Stress's reaction is triggered when an individual faces challenging situation and is unable to adapt to circumstances. Theories of organizational stress' cooper quoted Harrison's view: "Stress arises when the environment does not provide adequate supplies to meet a person's needs; or the abilities of the person fall short of demands that are prerequisite of receiving supplies" (Cooper).

Everly and Lating (2002) [5] proposed two types of stressors: the psychological stressor and the biogenic stressor. The first is taken place when a situation or stimulus has been perceived as a threat. The later happens when an individual does not need cognition or appraisal to procure a physiological reaction. Environmental context or caffeine for instances, may engender the same effect.

The transactional model of stress and coping by Lazarus emphasize the idea that stress is taken place when an individual perceives that the demands of external situation are beyond the personal and social resources that he or she is able to cope with or to mobilize [6].

Therefore, stress is considered as a particular transaction or an interaction between the individual and the environment that is assessed by the person as exceeding his or her resources, and it may put in danger his or her well-being. This implies the idea that neither the person's response nor the stimulus of the environment defines the so-called stress. Thus, stress might be perceived diffe- 
rently by people, and its impact is related basically in the person' own feelings of threat, vulnerability and the degree to which he or she may cope with the stressful events. Hence, the cognitive process affects the emotion engendered by one's own subjective interpretation.

This assumption might be taken to imply that there are two major cognitive appraisals that a person is supposed to consider, primary appraisal and secondary appraisal. Primary appraisal, according to Lazarus \& Folkman, (1984) [7] enfolds that a person assesses his or her situation as hazardous to his or her wellbeing. And, they specified that there are three types of primary appraisal:

- The appraisal may be seen as irrelevant as soon as the person is not interested in the outcome.

- The appraisal may be seen as positively benign when the person consider the situation as positive and has no negative impact on his or her well-being.

- The appraisal is seen as stressful as well as the person takes into account that the situation has a negative impact or circumstances are determined on his or her well-being.

Lewis (2001) [8] added to the above idea that an individual tends to focus on the magnitude of the situation as harmful.

Moreover, the secondary appraisal is about the individual's perception of his or her capability to handle the situation. There are three perspectives that person is more likely to focus on one of them: harm or loss, threat and challenge. Lewis (2001) [8] emphasized that harm implies the endurance of physical or emotional loss experienced by an individual. Else, threat entails the prediction of harm or loss that may occur in future time. Ultimately, there is a challenge which is marked by the positive potential of an individual to cope skillfully with stressful events or encounters [7]. The secondary appraisal cannot be assimilated separately from the primary appraisal; it is, in fact, related to it. Besides, it may be influenced by the factors disseminated within the context as similar as constraints, opportunities and demands [9]. As far as a situation is appraised by dint of personal resources, various kinds of emotions and meanings are insinuated. Subsequently, an endeavor emerges to allow the person coping with the situation.

\section{The Multidimensional Approach of Stress}

In starting point, this model of study involves the emphasis on environmental and socio demographic factors such as stressfulness of the everyday issues, social network and exposure to risk factors, else this model rely on the individual factors like life styles, personality characteristics, biographic and biomedical antecedents [10].

On the basis of this approach, two variables exist that allow the understanding of stress. Therefore, we distinguish the moderator and mediator [11]. At first, the mediator tends to describe the process by which an independent variable (VI) may be sensitively influential of the dependant variable (VD). Using this terminology, the VI is considered as the origin of the emergence of the action of 
the mediator or of its intensity, as well as the VD's response [11]. The major mediator variables are the perceived stress, the controlled stress and the coping.

The emergence of those variables comes out in dynamic way causing mutual and reciprocal adjustment. More specifically, the variables intervene strictly within the transaction between a person and the environment (this idea goes further with the limitation of the transaction model). On the other hand, Rascle \& Irachabal (2001) [11] argued that the process of stress can be seen as a juxtaposition of mediator variables in action, under the influence of VI (whether dispositional or situational), and this may produce harmful consequences on health. This kind of variable, attempts to alter the primary appraisal of the stressful event, and the related emotion. That's what we call the effect of feedback.

The moderator, on one hand, might be qualitative and quantitative. The first includes gender, race and context, and the latter implies the income level. It might affect the intensity's direction of the relationship between the VI and the VD. Therefore, moderator variable tends to change the relation between a predictor and a giving criterion.

\section{Strategies of Coping}

In an evidential way, several definition of this terminology exists. Thus, Lazarus \& Folkman (1984) [7] provide the current definition of coping as the cognitive and behavioral efforts that are constantly changing, and are destined to manage, tolerate and reduce internal and external stressors, that are appraised as exceeding one's personal resources. This highlights what a person is intending to do consciously within a situation assessed as psychologically stressing [7].

On this basis, we assimilate those efforts oriented toward an action as the attempts to manage environmental and internal demands, and the giving conflicts within those demands [12].

Therefore, coping strategies might be considered effective or functional when it allows an individual to manage the stressing situation or to reduce its impact on physical and psychological well-being, then to make sure that the situation is not ignited other problems.

This claim emphasizes that not only the coping strategy may find out a resolution for the problem, but also it tends to maintain and adjust negative emotions, specifically psychological distress [7]. This will lead to the idea that the effectiveness of coping is related to the nature of circumstances, the contextual background and the situational demands where a person ought to cope with [7] [10].

Coping necessitates adequate adjustment between the efforts of an individual, his or her principles, goals, beliefs and commitments. In case coping strategies were inappropriate with one's principals and aims, stressfulness might have been occurred.

Otherwise, ineffectiveness of coping occurs while an individual fails to wield emotional distress even if he or she has succeeded to handle the giving problem (coping related to substances' abuse like alcohol and drogues or high risk beha- 
viors) [13].

In sum, the efficiency of coping can be tested through the reduction of aggression and, the maintainability of physical and psychological well-being. The most important, eventually, is to cease producing further negative consequences. Dysfunctional coping seems to beget behavioral and physiological disorders in one's life [10]. In order to fully understand the usage of certain coping strategies, it is necessary to review the using cognitive theory and to provide insight through the giving enquiries; what type of coping is more effective to handle a stressful situation? Is it emotional focused coping or problem focused coping?

\section{Emotion focused coping}

Emotional focused strategy is used to deal with emotional distress in a giving cued situation. It occurs when an individual find out that the stressor is to be endured [14]. It targets emotional responses issued by the situation. Specifically, emotions are regulated in different ways: emotionally, cognitively, physically or behaviorally. Reponses may take several directions as the tendency to consume alcohol, cigarettes or drug abuses, also, when an individual tends to blame his or her self and feel responsible for the occurrence of the stressor. Besides, there may be an excessive propensity to express anxiety and upset. Other are associated with the commitment in certain diverse activities such as physical exercises, reading or watching TV. Furthermore, cognitively it attempts to alter the situation's significance in minimizing its impact or denying the reality through the retreat to magical thinking and fantasies, or denegation.

This kind of coping may in certain conditions foster the threat of someone's healthy life and may also put in danger the set in place of the adaptive behavior. This happens in case of denial or avoidance which makes it difficult to examine the symptoms and detect the inadequacy. It is possible that it can be exhaustive for the person's well-being. In what regarding the dimensions of emotional focused coping and life quality a study issued by Solmon et al. (1988) [15] argued that certain emotional strategies have more negative effects than others. Thus, Solmon has studied the effect of coping strategies handled by soldiers during the war of Lebanon over the standard life quality. This, in turn, has underlying the assumption that emotional strategy allows the prediction of the amount of difficulties faced subsequently, especially, with the context of social activities. This is resulted in the construct of unfavorable adjustment and then in interior unsatisfactory life quality.

\section{Problem focused coping}

The problem focused coping ( $\mathrm{PFC}$ ) is a manner to reduce situation's impediments and therefore to increase one's own resources for facing a giving issue. This is about the seek-out of knowledge in certain domains, plan of action, and data seeking. In fact, according to Lazarus \& Folkman (1984) [7] PFC included two factors which are problem resolution (seeking of information and making a plan), and the confrontation with the situation (efforts and direct actions to enhance the issue).

People who choose the problem focused coping, generally, tend to accommo- 
date with the encounter of stressor more adequately than those who focus on emotional focused coping [16]. This claim, highlights the conclusion that problem focused coping is associated with a satisfactory quality of life, and so the mental health.

\section{Emotion and Well-Being}

The term emotion has a thorough set of definitions that it seems evitable to mention them all. Since a long time, emotion was viewed only as a negative influence and hindrance to the perception and rational decision process. More recently, some researchers [17] [18] have stressed the importance of environmental, social, and emotional influences on cognitive strategies and decision-making. Thus, Scherer (1982) [19] defines emotion as the set of episodic variations within the different members of the organism, and in response to events assessed as important for that organism. Subsequently, according to the component process model (CPM), emotion process involves the synchronization of activities between five emotion components: the appraisal, the bodily reaction, the action tendency, the expression, and the feeling component. An emotion, as underlying by this model, is seen as "the model response markers" that enfold the frequent multi-component configuration of appraisals and the patterns of related responses. It is made by organized packages that are available to consciousness (in the form of non-verbal). The occurrence of some of these packages gives the pervasiveness of situations and, yields emotions of frustration, loss, achievement. Due to the human condition, the modal emotions have been referred to through universal linguistic labels, except for some particular interpersonal relations in some cultures. Then, the lexical and semantic expressions reflect the appraisal patterns and the response type within the emotional package.

Otherwise, Frijda (2006) [20] finds out that emotion is triggered by important events, especially, when they are related to a person's concerns. "An emotion is usually caused by a person consciously or unconsciously evaluating an event as relevant to a concern (an aim) that is important; emotion is felt as positive when a concern is advanced, and negative when a concern is impeded". This implies that the emotional process is based according to the readiness of somebody to act and, therefore, the willingness of plans [20]. More specifically, Frijda [20] considers that emotion is a process that necessitates a set of stages, and it is usually experienced as a distinctive kind of mental state. Emotion, in the other hand, may occur, at the same time, with bodily changes, expressions and actions. According to this author two conditions may take place; the necessary condition, without it an emotion cannot exist, and the sufficient condition which brings certainty that emotion is present. In summary, Frijda schematizes this as the occurrence of appraisal, then the context evaluation, the action readiness, the physiological change, expression and action.

Campos et al. (1994) [21] cite that "emotions are those processes which establish, maintain, change, or terminate the relation between the person and the environment on matters of significance to the person". This definition tries to en- 
tangle that emotion is "a guiding structure" of someone's life and his or her relationships with other people.

\section{Hedonic well-being}

This approach is based on the idea that well-being is the tendency to attain as maximum pleasure as one could, and therefore to avoid pain and displeasure. It is what we call the subjective happiness. It concerns also the evaluation and the judgment about what is good and what is bad. Kahneman et al. (1999) [22] argued that hedonic psychology is about what "makes experiences and life pleasant and unpleasant". Happiness through the lenses of Lucas (2000) [23] is designed through three components which are life satisfaction, positive mood, and negative mood. This suggests that all those components together can assure the ultimate outcomes that one could look for. This approach focuses on the subjective experience, and it claims that happiness and pleasure are specifically related to the expectation of individuals. Pleasure cannot be seen the same way by all, each person values what it might be. Otherwise, Aristotle deemed hedonism as a vulgar manner that transforms individuals into slaves of their desires and wants. One cannot transcend to ideal world and achieve what it is worth doing for the best of humanity. Additionally, Fromm (1994) [24] considered that optimal well-being is whether to feed needs and desires that are to be felt individualistically and to satisfied momentarily pleasure, or to realize human growth. In sum hedonic well-being can assure only subjective pleasure which cannot last forever.

\section{Eudaimonic well-being}

This approach is completely distinct from the previous one, and as such it is distinct from the subjective happiness. From this perspective, people are called to live according to their true nature and virtue. Waterman (1993) [25] claimed that well-being is achieved through the congruence between the true self (daimon) and the life experience. This idea relies on the personal expressiveness, to permit people living authentically, being alive and truly hold transcendental believes and deep values that bring growth and wellness to humanity. Ryff \& Singer $(1998,2000)$ [26], in their theory about lifespan of human flourishing, share the same idea and emphasized that well-being is achieved through the realization of a person's true potential and therefore struggling for perfection. Those researchers have found out that eudaimonism have an impact on health and can influence the immunological system. Thus, the emotional aspect is able to enhance and promote physical health. Well-being is tending to be considered as an indicator of health and good functioning of people. Rogers (1963) [27] emphasized that eudaimonic well-being is the fact of being fully functioning and not of being attaining pleasures and desires. So far, being eudaimonic is as well as being autonomous, competent and related. Rogers insisted also on the term of "valuation processes" which consists of the assessments of affect (positive or negative). According to his point of view emotions are related to appraisals of the life events and one's conditions and therefore appraisal is associated with respect to the self.

According to the self-determination theory by Ryan \& Deci (2000) [28] three basic psychological needs are provided to ensure well-being and personal 
growth. We find out autonomy, competence and relatedness. Through those three needs a person might have motivation, melting pot with the cultural practices and life satisfaction. Then, well-being may be fulfilled in taking into consideration the social environment that pushes people to thrive and progress whether psychologically or physically. For instance, within a suitable workplace an individual is called to experience self-realization and self-congruence and therefore to fell that he or she is valuable, producer and effective. Those feelings allow a person to achieve his true self and then wellness.

\section{Methods}

\section{Hypothesis}

When veterans experience high level of stress within their workplace they will be more likely to engage in problem focused coping and therefore fulfilling wellbeing.

When veterans experience high level of stress within their workplace they will be more likely to engage in avoidant coping strategies and therefore will not fulfilling well-being.

\section{Participants and procedures}

The study was conducted at the military hospital in Tunis. Participants were officers from different ranks (solider, corporal, corporal senior, sergeant, sergeant senior, adjutant, adjutant junior, adjutant senior, lieutenant, captain). During the first week of getting the consent from the major colonel of the psychiatric service in military hospital, participants were informed about the goal of the study. All of them were volunteered to collaborate. The sample consisted of twenty six participants, twelve men and twelve women. Some participants from higher ranks were not able to participate because they preserve.

Data of the current study were collected during two weeks. At baseline, participants completed a partly structured interview assessing their socio-demographic and occupational characteristic, containing the following data: age, marital status, gender, years of service, levels of education (secondary, university, and doctorate). Respondents were given a space to verbalize their emotions, to talk about their issues, to describe their performance and their relationships with coworkers and superiors within the workplace.

Participants were asked about why they choose to attend military services, about their relationships with coworkers and superiors and how they perceive their performance in a threatening context. Besides, coping strategies, perceived stress and well-being were measured by psychometric instruments.

\section{Measurers}

1) PSS Scale of Cohen et al.

Stress was measured with Cohen and Williamson (1989) [29] Perceived stress Scale. This scale incorporates 14 items including "Have you felt that you are controlling the situation", "Have you been concerned by an unexpected event". It is a 5-point Likert scale was used ranging from 1 (Never) to 5 (Always). It includes two sub-scales: perceived helplessness and perceived self-efficacy. Partic- 
ipants had to indicate the frequency of the happening of those items in the last couple weeks.

2) Coping scale of Paulhan

Participants were asked to complete the French version of the ways of coping checklist by Paulhan et al. (1994) [30]. This instrument has been widely used for the evaluation of stress-coping styles, and it presents proper psychometric measure in the original [31] and the adapted versions.

The current subscale was used to assess solving problem, social support, selfaccusation, positive reinterpretation and cognitive avoidance when encountering a difficult and stressful situation. Participants had to indicate which coping styles had been using. This scale has 29 items including "I hoped that a miracle happens", "I set a plan and follow it". It is a 4-point Goodman scale type ranging as such (No, already no, already yes, yes).

3) Psychological well-being scale of Masse et al.

Psychological well-being scale is an instrument constructed of 25 items that assesses the mental health and the different manifestations of well-being issued by Masse et al. (1998) [32].

The originality of this instrument concerns the evaluation of periods considered as best periods of mental health. It measures how enjoyable and satisfied life in terms of goals and motivation. This construct contains several subscales which is measuring self-worth (4 items) like "I have been feeling confident", it measures also the balance (4 items) such as "I have felt in balance emotionally", then we find the social engagement (4 items) for instance, "I have goals and ambitions", it checks sociability (4 Items) "I am a good listener to my friends", the subscale of self-control and environmental-control (4 Items) like "I have faced positively difficult situations" and ultimately we find the subscale of happiness including (5 items) "I have the impression that I am really enjoying my life". It is a Likert type scale in 5 points ranging from 1 as never and 5 almost every day.

\section{Results}

\section{Overview of data analysis}

A descriptive analysis of the subjects' socio-demographic characteristics was made; indicating means, standard deviation, medians, variance and percentile (see Table 1).

The variable distributions including that the perceived stress, coping styles and well-being were relatively skewed or kurtosis can be found in Table 2 .

The explanatory relation between the coping strategies, the perceived stress and the well-being was assessed through the Chi-square statistics. From this perspective, we consider coping styles (problem-focused coping and emotionalfocused coping) and perceived stress as independent variables, while the wellbeing is considered dependent variable, three models were constructed. The socio-demographic variables that possibly could influence our construct were controlled. To quantify the degree of the association between the dependent and independent variables $\mathrm{X} 2$ was calculated by applying its coefficients. Individual 
Table 1. Mean median, standard deviation and variance among study variables.

\begin{tabular}{ccccccc}
\hline & Age & Civil statut & $\begin{array}{c}\text { Years of ser- } \\
\text { vice }\end{array}$ & $\begin{array}{c}\text { Scholar } \\
\text { level }\end{array}$ & $\begin{array}{c}\text { Ranks of } \\
\text { officers }\end{array}$ & Gender \\
\hline N & 36 & 36 & 36 & 34 & 36 & 36 \\
Valid Missing & 0 & 0 & 0 & 2 & 0 & 0 \\
Mean & 35.92 & 2.56 & 1999.61 & 1.44 & 1.50 & 1.56 \\
Median & 34.00 & 3.00 & 2001.00 & 1.00 & 1.50 & 2.00 \\
Std. Deviation & 10.311 & 0.998 & 10.986 & 0.504 & 0.507 & 0.504 \\
Variance & 106.307 & 0.997 & 120.702 & 0.254 & 0.257 & 0.254 \\
Percentiles & 25 & 27.00 & 1.25 & 1989.00 & 1.00 & 1.00 \\
& 50 & 34.00 & 3.00 & 2001.00 & 1.00 & 1.50 \\
& 75 & 44.75 & 3.00 & 2009.25 & 2.00 & 2.00 \\
\hline
\end{tabular}

Table 2. Means, standard deviation, minimum, maximum, Skewness, Kurtosis among criterion variables.

\begin{tabular}{|c|c|c|c|c|c|c|c|c|c|}
\hline & $\mathrm{N}$ & Minimum & Maximum & Mean & $\begin{array}{c}\text { Std. } \\
\text { Deviation }\end{array}$ & Skew & ness & Kurt & osis \\
\hline & Statistic & Statistic & Statistic & Statistic & Statistic & Statistic & $\begin{array}{l}\text { Std. } \\
\text { Error }\end{array}$ & Statistic & $\begin{array}{l}\text { Std. } \\
\text { Error }\end{array}$ \\
\hline $\begin{array}{l}\text { Perceived } \\
\text { Stress }\end{array}$ & 36 & 1 & 2 & 1.28 & 0.454 & 1.036 & 0.393 & -0.985 & 0.768 \\
\hline Coping styles & 36 & 1 & 5 & 1.67 & 1.512 & 1.868 & 0.393 & 1.572 & 0.768 \\
\hline well-being & 36 & 1 & 4 & 2.03 & 1.207 & 0.564 & 0.393 & -1.370 & 0.768 \\
\hline $\begin{array}{l}\text { Years of } \\
\text { services }\end{array}$ & 36 & 1981 & 2015 & 1999.61 & 10.986 & -0.284 & 0.393 & -1.186 & 0.768 \\
\hline $\begin{array}{c}\text { Ranks of } \\
\text { officers }\end{array}$ & 36 & 1 & 2 & 1.50 & 0.507 & 0.000 & 0.393 & -2.121 & 0.768 \\
\hline Gender & 36 & 1 & 2 & 1.56 & 0.504 & -0.233 & 0.393 & -2.064 & 0.768 \\
\hline $\begin{array}{l}\text { Valid N } \\
\text { (listwise) }\end{array}$ & 36 & & & & & & & & \\
\hline
\end{tabular}

factors such age, gender, scholar level, ranks and length of employment were estimated by means and percentage of the calculation. The Shapiro test was used to check the conditional distribution of the population has fitted the normality. Data analysis was conducted through the usage of SPSS-16 statistical software package.

\section{Scores analysis}

A total of 26 respondents were included in the study. The mean age of participants was 35.92 years (Standard Deviation $[S D]=10.311$ ), with. The majority is married $58.3 \%, 25 \%$ are having not stable relationships, and $11.1 \%$ are divorced. Only $55.9 \%$ had achieved secondary level of education; $44.1 \%$ had achieved university and no one had held doctorate. We examined the link between the scholar level and the degree of the perceived stress; most participants who had achieved university level (44.1\%) have perceived helplessness stress 
(72.2\%), we find that $(\mathrm{X} 2=0.006, p<0.05)$. There is a significant link between the degree of perceived stress and the level of education. Also, in what concerns the relation between the new recruited-old recruited and the helplessness in perceived stress we found $(r=0.16, p<0.001)$, then there is a strong relation between those two factors. In what is related to the years of employment and the strategies of coping focused on problem solving and avoidance (X2 $=0.009, p<$ 0.05). The old recruited have reported that they tend to use solving problem coping when new recruited tend to use avoidance coping. At the same time, we found out that the years of employment have a strong relation with the quality of well-being (X2 $=0.010, p<0.05$ ), the link between well-being and ranks seems to be positively significant $(\mathrm{X} 2=0.001, p<0.05)$ the senior workers tend to have more self-esteem (11\%) than the new ones (8\%). When we asked the veterans if they tend to ignore that they have an issue, we noticed that men are more oriented to ignore issues than women. Then, the link between gender and ignoring the problem is quite significant, value of $\mathrm{X} 2=7.193, \mathrm{df}=2(\mathrm{X} 2=0.004, p$ $<0.05)$.

The statistical analyses (Figure 1) put in evidence a score difference between the problem solving coping $83.3 \%$ and the avoidance coping $16.7 \%$, respectively with $22.2 \%$ for the sergeant chief and different score $13.9 \%$ for the adjutant and the major adjutant.

Otherwise, the Khi2 statistics allow to set a link between gender and coping strategies, but in our sample results showed no significant link $(\mathrm{X} 2=0.230, \mathrm{p}>$ 0.05). It indicates that there is no difference between men and women. They tend to use the same coping style.

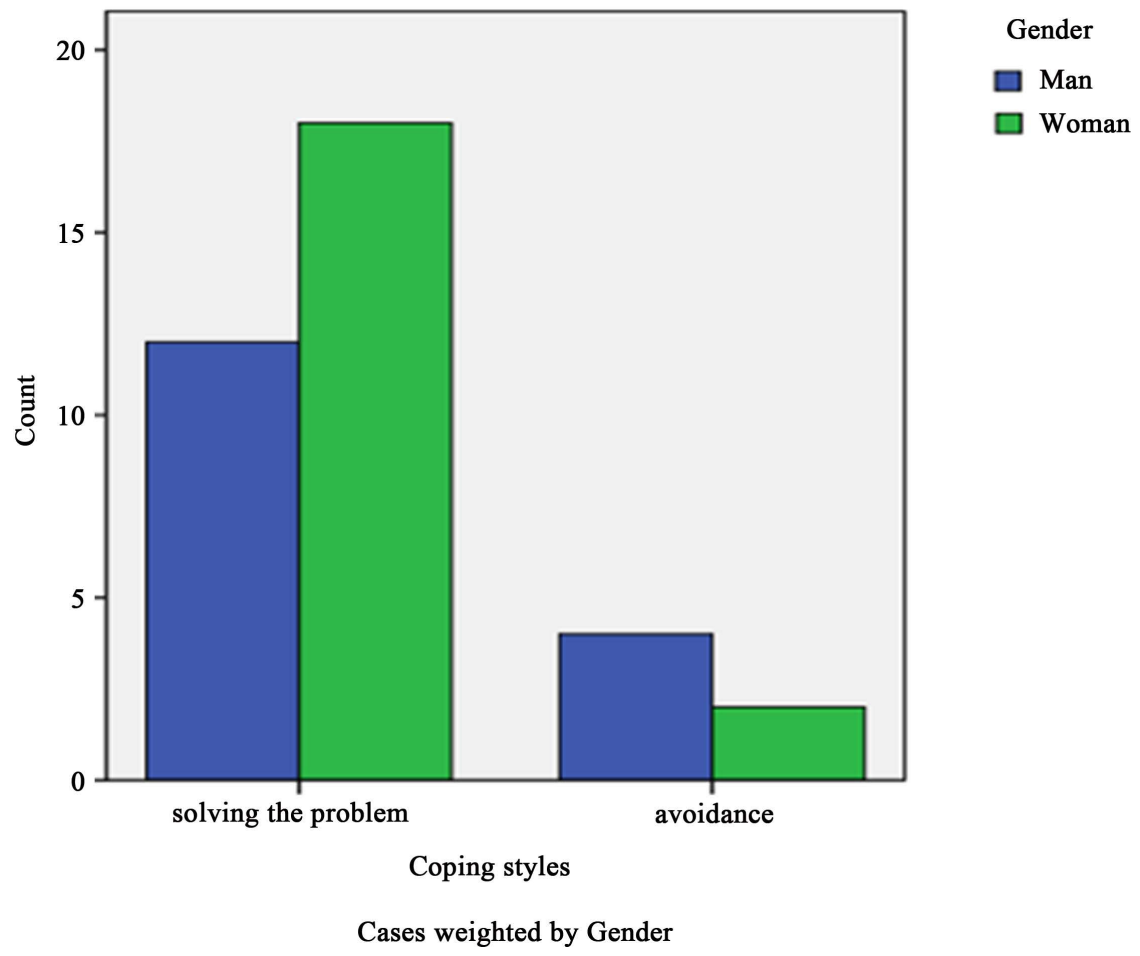

Figure 1. Chart demonstrating coping styles with sex differences. 
In addition, $60 \%$ of our sample has reported that they perceive the actual situation with the country as dangerous, while $40 \%$ considered as not threatening; although, $61.8 \%$ claimed that they are optimistic about the future. $69.4 \%$ reported they have felt signs of stress when $11.1 \%$ said sometimes and $19.4 \%$ did not. When we examined the relation between gender and the ignorance of the actual issues the result showed a relevant link $(\mathrm{X} 2=0.004, p>0.05)$. Moreover, $55.6 \%$ of the sample wished that all their issues disappear like by magic, while $44.4 \%$ do not. $61.1 \%$ assured that the tensions and conflicts within the couple have increased. $77.8 \%$ claimed that they receive support from family.

In addition, when we asked the participants about the characteristics of a good military $90.9 \%$ answered discipline, while $82.9 \%$ insisted that they do not have relational difficulties with the hierarchy. The chi-square test reveals a non-significant relation between the discipline and difficulties with the hierarchy $(\mathrm{X} 2=$ $0.19, p>0.05)$.

\section{Discussion}

The purpose of this research was to discover the type of coping strategy used by a sample of military and its contribution to psychological well-being within a stressful context, especially, with the uncommon circumstances that the country goes through. First of all, we tried to investigate the differences between low rank and higher rank of military, as well as the length of employment and sex differences.

The major finding of the study suggests that the length of employment has statistically significant association with coping style, well-being, and perceived stress.

Only two coping styles, avoidance and solving problems emerged as significant mediator between length of work service and well-being. The main hypothesis of this study is about which coping strategy were veterans more likely to use in face of a context appraised as demanding.

The study examined the role of seniority in coping strategies as a direct moderator to enhance well-being. To our knowledge, no previous study has examined the association between the lengths of employment, ranks, gender and the coping strategies within the military institution. This study has identified that both male and female use the same style of coping which are problem solving and avoidance, notably, women were more likely to use problem solving than men. Also, women's scores on self-esteem were higher than men's. Despite of the high self-esteem existing among the military personal, feeling of happiness was completely absent. In sum, Tunisians military had a specific conception of happiness' concept, which is associated to extrinsic factors.

Obviously, this can be explained by the same type of training that male and female undergo during the preliminary physical exercises and because women have to coexist in a predominantly male environment. This claim goes in line with the idea that military personal are inflicted to a large range of stressors as a portion of their work responsibilities and assignments. Apparently, women in 
this sample do appraise the contextual environment where they work as taxing since they do not have enough time for their families or children, to them; this is a psychological challenge of their jobs. They cannot disobey assignments that sometimes exceed 24 hours, and at the same time they tend to feel preoccupied by their families. This may imply the importance of cognitive appraisal. On this basis, the military organization treat female the same way as male, this can lead to the assumption that there is no difference between them and they are supposed to answer to the demanding situation similarly. More specifically, the coping strategy used by the veterans is acquired through the training period, and this explains their similarities. Besides, men reported that the higher stress is related to the workplace more than to their families, especially with long hour's duty. It's a heavy pressure on their physical health, as well as their mental health.

Solving problems is a mechanism that allows them to confront the situation. This evidence does not adhere to several studies that deemed women are more likely to use emotional coping.

Findings have shown self-esteem among military cohorts but no positive affect or happiness. This is to tell that the absence of decisional autonomy which is supposed to moderate the relationship between perceived stress and well-being, is inhibiting them to achieve eudaimonic state of being. Besides, the majority of the sample described the current situation within the territory as dangerous. Therefore, this is plausible that they evaluate the situation as threatening. It is quite clear that despite of the existence of the hazardous context military expressed that they are optimistic about the future. This may be explained that the risk undergone seems to be a part of the job's duties.

This study's modal evaluated the association between the length of employment and ranks of veterans with the coping styles to examine their relation with the fulfillment of the will-being. In coherence with past studies, the persistence with using the same coping strategy even in absence of traumatic or demanding context is able to reduce the effectiveness of the organism to face new dangerous events. The results of this study highlight the propensity of the participants to vacillate only into two major coping strategies (problem solving and avoidance), and excluding the positive evaluation, the social support and self-accusation. The exigency of high demanding job necessitates obviously high level of availability. Therefore, some of our sample tries avoidance as coping strategy. This is a way to eliminate their emotions or even to deny it. They thought that they are controlling the stressful transaction by minimizing its impact and this why the majority has reported that they find difficulty to express themselves, since they are repressing themselves all the time. The avoidant coping relies on a defensive attitude and distraction. In fact, this might be exhaustive for their mental health. This could possibly providing insight into the ability of those persons to realize personal growth and self-determination. So often, researchers (Tamres et al., 2002) [33] believe that men tend to adopt an attitude more oriented to escape from problems or to avoid. Such an attitude cannot be effectively healthy but possibly hazardous for the well-being in the far-reached period. In previous 
study, the focus on avoidance is related to the perception of lack of development and behavioral disengagement (Montero-Marin, 2014) [34]. It's the lack of ambition; a military is prevented to achieve his or her study after being recruited by the institution. In fact, they are called to stick to their grade without the giving hint to achieve progress or self-development. The only output that a military personal may gain when passing from a grade to another, is more responsibilities and hard work but not personal satisfaction. Truthfully, individual satisfaction is what all those military personal lack. There is not a balance between output and input.

As a matter of fact, rank and length of employment seems to be crucial an as effort to understand the relation stress-coping-well-being. While all the participants whether new recruited or old recruited, low rank or higher rank have indicated the same degree of stress, which is helpless perceived stress, eventually it is important to check its association to coping and psychological well-being. The relevant link between coping and years of employment refers to the factor of relatedness. As long as a military assures his function within a group, that he or she belongs, the more they feel related to that profession. The melting pot within the culture and rules of the military institution allows a veteran to adopt the same perception of stress and the same use of coping.

A military has to adhere to these shared beliefs in order not to be sanctioned or excluded. This involve that the majority of the participants have self-esteem but no social engagement. Generally speaking, military cohorts admitted that they do not have relational difficulties with the higher grades. The majority of them considered a good military as the one who adheres to discipline. Thus, there is a submission to the higher ranks under a strict discipline. This involves the idea that military personal were restricting their autonomy in order to follow orders. It happens that they showed good endeavor but this cannot ensure psychological well-being. Otherwise, this can be exhaustive for their capability to adjust with the social environment and healthy couple or family relationships. This is why a great deal of them had mentioned signs of stress like anxiety, insomnia, depression, and consuming so many cigarettes and drinking coffee.

Further research is necessary to investigate the coping-psychological well-being especially in barracks and in the battle field. As well, a longitudinal study is necessary in order to fully understand how veterans respond to the taxing context and how they tend to realize psychological well-being.

Although, they have problems solving coping and high level of self-esteem, military cohorts do not prove any slight of happiness or self-satisfaction or even feeling of self-development. No difference between men and women, or either high or low ranks or both new and old recruited regarding the appraisal of stress, but certainly there is a great similarity concerning the lack of happiness.

\section{Limitations and Conclusion}

Several limitations of this study should be mentioned. In starting point, this study did not assess the personality trait which might be a determinant factor in 
explaining the tendency of the participants to be optimistic or more oriented to problem focusing coping. Else, the sample of this study was quite small, so the salient results may not be very precise about the whole population of the military. A very tough impediment had encountered us from the beginning which was the difficulty to get access to the military institution. It is worth noting, in this regard, that this study aimed to investigate the relation between coping styles and psychological well-being under stress. Very few studies have targeted this issue within Tunisia. It is important to highlight the total absence of happiness among our sample which requires further research to better understand this finding.

\section{References}

[1] Carver, C.S. and Scheier, M.F. (1994) Situational Coping and Coping Dispositions in a Stressful Transaction. Journal of Personality and Social Psychology, 66, 184195. https://doi.org/10.1037/0022-3514.66.1.184

[2] Selye, H. (1956) The Stress of Life. McGraw-Hill, New York.

[3] Cannon, W.B. (1994) Reflections on the Man and His Contributions. International Journal of Stress Management, 1, 145-148.

[4] Griffin, R.W. and Moorhead, G. (2009) Organizational Behavior: Managing People and Organizations. 9th Edition, Cengage Learning, USA.

[5] Everly, G.S. and Lating, J.M. (2002) A Clinical Guide to the Treatment of the Human Stress Response. 2nd Edition, Kluwer, New York.

[6] Lazarus, R.S. (1966) Psychological Stress and the Coping Process. McGraw-Hill, New York.

[7] Lazarus, R.S. and Folkman, S. (1984) Stress, Appraisal, and Coping. Springer, New York.

[8] Lewis, S.J. (2001) A Crisis State Assessment Scale: Development and Validation of a New Instrument. Dissertation Abstracts International, UMI No. AAT3034054, $1-128$.

[9] Lazarus, R.S. (1999) Stress and Emotion: A New Synthesis. Springer, New York.

[10] Bruchon-Schweitzer, M. and Dantzer, R. (1996) Introduction à la psychologie de la santé. Sciences sociales et santé, 14, 117-121.

[11] Rascle, N. and Irachabal, S. (2001) Médiateurs et modérateurs: Implications et méthodologiques dans le domaine du stress et de la psychologique de la santé. Le Travail Humain, 64, 97-118. https://doi.org/10.3917/th.642.0097

[12] Lazarus, R.S. and Et Launier, R. (1978) Stress-Related Transactions between Person and Environment. In: Pervin, L.A. and Lewis, M., Eds., Perspective in Interactional Psychology, Plenum, New York, 287-327. https://doi.org/10.1007/978-1-4613-3997-7 12

[13] Zeidner, M. and Saklofske, D. (1996) Adaptive and Maladaptive Coping. In: Zeider, M. and Endler, N., Eds., Handbook of Coping. Theory, Research, Applications, John Wiley and Sons, New York, 505-531.

[14] Folkman, S. and Lazarus, R.S. (1980) An Analysis of Coping in a Middle-Aged Community Sample. Journal of Health and Social Behavior, 21, 219-239. https://doi.org/10.2307/2136617

[15] Solmon, Z., Mikulincer, M. and Avitzur, E. (1988) Coping, Locus of Control, Social Support, and Combat-Related Posttraumatic Stress Disorder: A Prospective Study. 
Journal of Personality and Social Psychology, 9, 456-472. https://doi.org/10.1037/0022-3514.55.2.279

[16] Holahan, C.J., Moos, R.H. and Schaefer, J.A. (1996) Coping, Stress Resistance, and Growth: Conceptualizing Adaptive Functioning. In: Zeider, M. and Endler, N., Eds., Handbook of Coping. Theory, Research, Applications, John Wiley and Sons, New York, 24-43.

[17] Naceur, A. (2010) Quand l'émotion perçoit et décide. In: Masmoudi, S. and Naceur, A., Eds., Du percept à la décision, DeBoeck Supérieur, Brussels, 25-49.

[18] Naceur, A. (2013) Emotion et Apprentissage: De la théorie à la pratique. CPU, Tunis.

[19] Scherer, K.R. (1982) Emotion as a Process: Function Origin, and Regulation. Social Service Information, 21, 555-570. https://doi.org/10.1177/053901882021004004

[20] Frijda, N. (2006) The Laws of Emotion. Psychology Press, Hove.

[21] Campos, R.V., Lee, Y.C. and Drucker, D.J. (1994) Divergent Tissue-Specific and Developmental Expression of Receptors for Glucagon and Glucagon-Like Peptide-1 in the Mouse. Endocrinology, 134, 2156-2164. https://doi.org/10.1210/endo.134.5.8156917

[22] Kahneman, D. (1999) Objective Happiness. In: Kahneman, D., Diener, E. and Schwarz, N., Eds., Well-Being. The Foundations of Hedonic Psychology, Russell Sage Foundation, New York, 3-25.

[23] Lucas, R. (2000) Understanding Extraverts' Enjoyment of Social Situation: The Importance of Pleasantness. Journal of Personality and Social Psychology, 81, 343-356. https://doi.org/10.1037/0022-3514.81.2.343

[24] Fromm, E (1994) Shaper of the Human Condition. Palgrave Macmillan, London.

[25] Waterman, A.S. (1993) Two Conceptions of Happiness: Contrasts of Personal Expressiveness (Eudaimonia) and Hedonic Enjoyment. Journal of Personality and Social Psychology, 64, 678-691. https://doi.org/10.1037/0022-3514.64.4.678

[26] Ryff, C.D. and Singer, B.H (2008) Thy Self and Become What You Are: A Eudaimonic Approach to Psychological Well-Being. Journal of Happiness Study, 9, 13-39. https://doi.org/10.1007/s10902-006-9019-0

[27] Rogers, C. (1963) The Actualizing Tendency in Relation to "Motives" and to Consciousness. In: Jones, M.R., Ed., Nebraska Symposium on Motivation, University of Nebraska Press, Lincoln, 1-24.

[28] Ryan, R.M. and Deci, E.L. (2000) On Happiness and Human Potentials: A Review of Research on Hedonic and Eudainmonic Well-Being. Annual Review of Psychology, 52, 141-166. https://doi.org/10.1146/annurev.psych.52.1.141

[29] Cohen, S. and Edwards, J.R. (1989) Personality Characteristics as Moderators of the Relationship between Stress and Disorder. In: Neufeld, W.J., Ed., Advances in the Investigation of Psychological Stress, Wiley, New York, 235-283.

[30] Paulhan, I. and Bourgeois, M. (1995) Stress et coping. PUF, Collection Nodules, Paris.

[31] Vaillant, G.E., Bond, M. and Et Vaillant, C.O. (1986) An Empirically Validated Hierarchy of Defense Mechanisms. Archives of General Psychiatry, 43, 786-794. https://doi.org/10.1001/archpsyc.1986.01800080072010

[32] Massé, R., Poulin, C., Dassa, C., Lambert, J., Bélair, S. and Battaglini, A. (1998) Élaboration et validation d'un outil de mesure du bien-être psychologique: L'ÉMMBEP. Revue Canadienne de Santé Publique, 89, 352-357.

[33] Tamres, L.K., Janicki, D. and Helgeson, V.S. (2002) Sex Differences in Coping Be- 
havior: A Meta-Analytic Review and an Examination of Relative Coping. Personality and Social Psychology Review, 6, 2-30.

https://doi.org/10.1207/S15327957PSPR0601 1

[34] Montero-Marin, J., Pardo-Abrill, J., Demarzo, M.M., Gascon, S. and Garcia-Campayo, J. (2014) Coping with Stress and Types of Burnout: Explanatory Power of Different Coping Strategies. PLoS ONE, 9, e89090.

https://doi.org/10.1371/journal.pone.0089090

Submit or recommend next manuscript to SCIRP and we will provide best service for you:

Accepting pre-submission inquiries through Email, Facebook, LinkedIn, Twitter, etc. A wide selection of journals (inclusive of 9 subjects, more than 200 journals) Providing 24-hour high-quality service User-friendly online submission system Fair and swift peer-review system Efficient typesetting and proofreading procedure Display of the result of downloads and visits, as well as the number of cited articles Maximum dissemination of your research work

Submit your manuscript at: http://papersubmission.scirp.org/

Or contactwjns@scirp.org 